\title{
The Client-informing Policy in E-commerce System
}

\author{
Janina A. Jakubczyc, Violetta Galant, and Maria A. Mach \\ Wroclaw University of Economics, Poland
}

\author{
janina.jakubczyc@ae.wroc.pl galant@ae.wroc.pl maria.mach@ae.wroc.pl
}

\begin{abstract}
Our proposal is to work out the client-informing policy that will guarantee success for e-commerce and provide significant utility to the customers. This idea is motivated by a need to create a marketing tool that will include marketing features that are not represented by currently existing supporting tools for ecommerce, e.g. different kinds of recommender systems. They have only local character in the light of the whole e-commerce system. The perspective of the client-informing policy links other fe atures that affect e-commerce activities. We focus on the task of determining the policy structure.
\end{abstract}

Keywords : e-commerce, management policy, informing policy

\section{Introduction}

The success of e-commerce depends on many factors. The main one is to find a way to sell the most and to have the goods that are wanted the most. In this case it is necessary to apply modern marketing, which is "...designed not only to maximize utility to the customer but also to maximize value to the business at the same time", as J.B. Schafer et al. have written in "E-Commerce Recommendation Applications" (Schafer, Konstan \& Riedl, 2001). E-commerce should be seen as an important source of effectiveness and of innovation, and a new way to create new value in the organization. Such a perspective will allow seeing the whole picture of e-commerce, not only the customer side. E-commerce business depends more heavily on information advantages than traditional commerce; thus, information is the key for ecommerce.

Client informing policy will be one of the e-commerce strategies. The approach that exists nowadays in e-commerce evolved in response to the growing set of products, services and information choice opportunities. Also important was consumer frustration caused by a decrease of professional support for making these choices (Kohavi \& Provost, 2001). But the above approach should - in our opinion - take into account also the business (not only customer) side of e-commerce. The success of e-commerce depends first of all on its customers, but it is also necessary to add some other elements. One of those elements is the proposal of taking advantage of direct interaction with customers in order to improve the supply side of e-business. This interaction can be used to dynamically modify product assortments, virtual product displays, and other merchandising interfaces; even product assortments can be personalized to individual customers. Customers should affect the acquisition of products and available products should affect the

Material published as part of these proceedings, either on-line or in print, is copyrighted by Informing Science. Permission to make digital or paper copy of part or all of these works for personal or classroom use is granted without fee provided that the copies are not made or distributed for profit or commercial advantage AND that copies 1) bear this notice in full and 2) give the full citation on the first page. It is permissible to abstract these works so long as credit is given. To copy in all other cases or to republish or to post on a server or to redistribute to lists requires specific permission from the publisher at Publisher@Informingscience.org customers. E-commerce can influence or even shape the preferences of the client in the longterm.

This perspective requires linking information from different elements of the e-commerce system that come from different parts of the system (i.e. supply system and customer service system). The client-informing policy should allow the control of the e-commerce system in a balanced way. It 


\section{Client-informing Policy}

should assure the exchange of management information for monitoring and control between the interacting sub systems and environment. In our earlier work, we have conceptualized the e-commerce functionality in terms of a supply support and a customer support subsystem interacting via a communication channel (for more details see: Galant, Jakubczyc \& Paprzycki, 2002, Gordon, Jakubczyc, Galant \& Paprzycki, 2002).

The problem presented is interesting and it will bring the ability to run e-commerce business with less effort. Our long-term aim is to investigate the effectiveness of the defined client-informing policy.

This paper is organized as follows: in the second section we explain the terms client-informing policy and e-commerce; the third section is about categories of information in e-commerce and about information receivers; in the fourth section we introduce sources of significant information; in the next two section we try to identify the possible place to incorporate elements of client-informing policy in the context of content of information categories; and the last section is about possibilities of client-informing policy evaluation. The summary includes some observations and looks in the future research.

\section{Definitions of Client-informing Policy and E-commerce}

The terms "client-informing policy" and "e-commerce" need some kind of introduction, because these expressions carry many meanings. First let us refer to the e-commerce concept. There are many definition of it that differ significantly with respect to the activities or type of transactions and the communication infrastructure on which these activities / transactions are carried. The discussions on this concept can be found, for example, in Colecchia (1999), Gregor and Stawiszynski(2002) and Szpringer (2002). The definitions presented there are broader (e.g. include most of the different layers of economic activity such as commerce, marketing, information services, health, education, and so on) or narrower (e.g. only retailing or delivery occurring electronically). We refer to the latter one that can be expressed as follows:

e-commerce is the selling and buying process of products and services conducted on the base of Internet technology.

But even this concept includes more detailed types that are as follows: business to business (B2B), business to customer (B2C), and yet less popular but already existing - customer to bus iness (C2B), business to administration (B2A), customer to customer (C2C) (e.g. see Gregor \& Stawiszynski, 2002). We focus on the business to customer relations (transactions).

The client-informing policy refers to the goal that should be achieved by e-commerce as a whole. This goal splits into two contradictory sub-goals. The first is to meet client expectations. The second is to guarantee the success of e-commerce. The term client-informing policy can be split into two independent parts: activities - 'policy' and the subject of policy - 'client informing'. The word 'policy' means a course of actions that would support at the same time the interest of client and e-commerce. The words "global" and "long-term" describe important properties of client-informing policy.

The words "client informing" refer to the subject of policy; the policy should be expressed through information that has been delivered to the customer. This information should encourage the client to buy what he or she would like to buy and e-commerce system to sell it.

The term 'policy' outlines the global character in contradiction to partial solutions as different kinds of recommendation systems that have only local character (see Schafer, Konstan \& Riedl, 2001; Resnik \& Varian, 1997; Balabanovic, 1997) in e-commerce systems. 


\section{Information Categories in E-commerce}

The client informing policy determines what kind of information should be available, and to whom. The first attempt is to determine the type of information that can be delivered to the web visitors. There are three information categories (see Galant, Jakubczyc \& Paprzycki, 2002) that refer to:

a) the direct sale;

b) the advertisements of external products and services;

c) the value-added information.

The first category explicitly refers to the basic e-commerce activities that are: recommendations, adve rtisement and catalogs of products. The goal of these activities is to encourage the customers to buy products or services using e-commerce. The common and most popular approaches are based on the idea of recommender systems that are directed at one-to-one sales, thus are limited to virtual salespeople. A recommender system is used by e-commerce sites to suggest products to their customers and to provide consumers with information to help them decide which products to purchase (Schafer, Konstan \& Riedl, 2001). The existing recommender systems represent three approaches - content-based (Balabanovic \& Shoham, 1997), collaborative (Sarwar, Karypis, Konstan \& Riedl, 2000; Lee, 2001), and mixed (Balabanovic, 1997; Good, Schafer, Konstan, Borchers, Sarwar, Herlocker \& Riedl, 1999). There has been a great effort to develop these systems. They make use of many techniques, from simple statistic correlation through information retrieval, data mining, and knowledge discovery up to learning algorithms. However, there exist still unsolved problems that concern: scaling and sparse problem, new user and recurring startup problems that can affect correctness of results and acceptable time to reach solutions.

The advertisement of products through e-commerce may be directed to individual customers while browsing the catalog and selecting the items to purchase. This form is very seldom used as of yet, but it can be used to promote new products to the customer or to guess the customer wishes. It is a very promising solution that could make a customer more interested in the e-commerce offer if only that customer is eager to follow the advertisements.

The advertisement of products can take place inside and outside a given e-commerce site (different media or other websites). The goal of it is to encourage consumers in different segments to purchase product from categories selected by the marketer of e-commerce.

The catalog of products available on the website is the complete offer of e-commerce. The form and contents are customized to the needs of users and e-commerce.

The second category refers to the important activity of each business on the Internet (net environment generally). The advertisements of external products and services are newly available sources of profits. It can affect the customers too - they can choose it. They may like it or it can bother them.

The third category refers to the problem of how to additionally encourage customers to enter and to stay with a given website. This category does not bring explicit utilities for e-commerce, but attracts attention and gives some simple pleasure to customers. It can be used also to arouse interest in new area that can be significant to e-commerce business.

The next issue refers to information receivers. The identification of customer or groups of customers that would be homogenous according to appropriate information (e.g. toys for group of kids) is the key issue. The first partition concerns individual and grouped clients. The groups of clients are created with common characteristics - so called stereotypes, and groups with common interests - so called communities. Preparing information (recommendation, advertisement) for individual customers, in principle, is the subject of direct sale-related activities. The groups of customers refer to all three information categories mentioned above. 


\section{Client-informing Policy}

Another partition of customers may distinguish groups of clients taking into consideration their behaviors on the website. For an e-commerce perspective, it would be convenient to have the possibility of identifying the following groups of users: short-term visitor, active investigator and customer (Spiliopoulou \& Pohle, 2001). The analysis of the first two groups could find the reasons that would lead to improving relations between e-commerce and users. It would help to find a way to turn visitors into customers.

Another distinction concerns the client and the mediator. The mediator can be an agent that acts on behalf of someone else. It can be software or a human agent. The appearance of a software agent as a mediator acting on behalf of a customer can change the requirements: e.g. a software agent by now can't "see" an image of a website and thus does not count for it; moreover, agent's susceptibility on advertisement and recommendation can be very low or none. The direct and indirect customers are other names for above distinction that are used for example in Ardissono \& Goy (2001). The mediator can represent more than one user, thus identification and personalization for such type of customer would be more difficult. Each of these groups may require a different approach.

\section{Sources of Information}

The described categories of information in the above section deal with different tasks. But each of these kinds of information is a key for e-commerce success. The efficacy of them depends on the accuracy of knowledge that is incorporated in them. Together with the choice of appropriate individual or group customer it makes the first step in developing a client-informing policy.

The issue now is to determine the data / information / knowledge sources. There can be taken into account customer and product sources which can be found inside and outside a given e-commerce and in its environment that can affect (directly and indirectly) customer's behavior and the offers of products and results of research in the area of market of customer and product.

The most valuable, desired and fundamental information concerns the customers. The difficulties of this information refer to tremendous variety and to significant changeability and lack of precision in expressing customer's preferences. There are two approaches to acquisition of such information: 'invasive' and 'non-invasive' methods. The first one refers to active involvement of the user, i.e. through questionnaires and in-vivo experiments simulating the site's expected usage. Information acquired in this way is very valuable.

In the 'non invasive methods, information about the users of the website is obtained through mechanisms recording the users' behavior and does not require the user's interaction. The primary source for this purpose are server logs that can be enhanced by the observations of the client. Other data can be collected from demographic data and customer records. The scoutings of the client environments make possible the identification of the customer segments. The additional sources of information, besides the domain knowledge, are different kinds of market research conducted by its own market department or by various institutions. Recording all gathered data / information and knowledge in its own databases and data warehouses makes it possible to get to know the customers and their behaviors and preferences. The preference of the client is mirrored by expectations, needs, habits, inclinations, lifestyles and beliefs. Client preferences are identified, applied and verified by data collected about customer transactions and customer behavior on the web of e-commerce. The client informs in various ways about his (hers) demands, conditions and expected realization of them.

Another subject of collecting data concerns products that are available. While collecting data about product in some areas one has to take into account the rate of technological change, which determines changes in products on the markets (short product lifecycle). In some brands the rate of change is so high that it should be reflected in the information about products, i.e. product's characteristics could 
contain only those features that change quickly. Information about them is collected and organized according to different perspectives of customers. Description of product is done by applying all possible properties that are of various meaning to the customers. The information concerns, first of all, records of sold goods, and about the new and withdrawing goods, the states of their supply and the ways of delivering the products to clients.

The important information are different kinds of events that affect client's preferences and can be used to choose (filter) from recommended products or can be used as additional important advertisement or as a means to increase the sale of given products. Regarded events can be relevant or not relevant to ecommerce activities but they affect it.

The first group of events includes common holidays, important events and their anniversaries, and also the seasons. Although they are not directly involved with the e-commerce activity, they may affect the client preferences. The example of such situation is Christmas where the role of client informing policy is to recommend and advertise the products as e.g. Christmas presents or so like. The information of such events spreads on other elements of e-commerce as e.g. delivery service that should use Christmas wrappers.

The next group of events contains events that can be directly used by the e-commerce, for e xample as the reason to purchase the products that client is not interested in, if it is the book by a Nobel Prize winner. Such events arouse temporal interest in work of arts and literature by the honored authors. Not all of such events can be foreseen. Thus there is a need to supplement and predict possible events as they are coming.

\section{Categories of Information Content}

In the process of distribution, the information gathered can take one of the following forms:

- adve rtisement (inside and outside e-commerce);

- recommendation;

- value-added information;

- catalog of available products.

The advertisement plays the role of product recommendation on behalf of the e-commerce system. Us ually it is addressed to mass or group customers. Now the advertisement is more frequently found as an element of a recommender system.

The recommendations are the basic form of transferring information to all users of the e-commerce system. In everyday life, we rely on recommendations from other people, either by word of mouth, recommendation letters, movie or book reviews printed in newspapers. Recommender systems assist and augment this natural social process (Resnik \& Varian, 1997). The recommendations are presented during the support process of client service. Their form and content depend on gathered knowledge about the client, on-line client behavior, and on information about the system preferences.

The recommender systems can assist browsing systems. The on-line recommendation may be divided into a three-stage process (see Balbanovic, 1997):

- collection - to collect the items to be recommended

- selection - to select from collected items those best for particular user

- delivery. 


\section{Client-informing Policy}

The second point - selection is the action that can be linked or supported by factors from outside recommender system.

The value-added information concerns real customers and it can be treated as some kind of reward but it can be the easy means to reach potential customer for desired by e-commerce product.

The bulletins contain complete information. Because the quantity of the information can be too large, there is the additional possibility to make available on-line some means for information filtering, viewing the filtered data and the possibilities to copy them. The information on request is completed according to client requirements that are specified in the appropriate prepared questionnaire.

\section{An Attempt for the Formal Representation of Some Determinants of the Client-Informing Policy in E-commerce}

We propose work out appropriate indicators (determinants), which can be linked with the contents of advertisements, recommendations, value-added information and online bulletin of products. The rough list of such determinants is as follows:

- indicator (rate) of sold products;

- calendar of events that do not directly affect e-commerce;

- calendar of events relevant to e-commerce activities.

The indicator of sold products determines the level of those products' activity in the process of filtering recommendations that will be presented to users. It is calculated for all goods on the basis of the time analysis of sale quantity. The indicator of sold products is included in additional field in the record that describes a product. Its value is expressed in the range 1-10. We have taken into consideration the use of the weights to incorporate broader context and making the indic ators comparable across product base.

The next two indicators have the same structure, namely they consist of identical parts but can have different number of events in the sequence. Each of these parts includes: the event 'tag', 'period in advance' and 'current state'. The field of 'current state' can access three values that grade closeness of the events: $0,1,2$. Zero means that an event will not be active in the near time. Number 1 means that there should be launched the preparations to the coming event, number 2 means that there is the activity time. These indicators are developed on the basis of system clock; therefore it is possible to produce a calendar of general events and a calendar of events connected directly (relevant to) with given e-commerce activity.

Specific contents created on the given occasions refer to each indicator. We have to take into consideration also the hierarchy of events in the case of events overlapping. In the case of the second indicator, there is not always possibility to prepare in advance the content of the recommendations but partially it will be possible.

The three indicators that we have presented together with the whole offer of sold product are sufficient for maintenance of the general and thematic recommendations. The current analysis of the client responses on the presented recommendations is the mean of their verification.

The recommendations are much difficult to formalize than these introduced above. The problem concerns first of all, the possibility of activating the recomme nder system. There are two main groups of clients that should be regarded. The customers from the first group determine exactly what they are looking for and they do not expect any suggestion from the system. In this case there is only the place to present advertisement that can be directed if the client was recognized. The second group makes specifications of the wanted goods on the different levels of ambiguity. Thus there are various possibilities to incorporate e-commerce preferences. The y depend on the level of ambiguity that determine the gap that 
client leaves to fill. In such cases the important thing is how detailed are the keywords used by the client. From the one hand the breathiest is the gap the bigger is the range of possibilities of recommendations but from the other hand to cope with too many possibilities not always means the better situation.

As we mentioned above, there are two forms of client informing. The first one is the advertisement and the second is recommendation. The first is determined by the needs of system but it can be directed on the basis of knowledge possessed about customer's preferences and thus produce appropriate advertisement. In this case from the system perspective there are more different possibilities, which means more loose treatment of the client interests. There can be attempts to encourage the client to buy goods that never aroused his attention and thus they allow investigating an unknown client's needs.

The latter one starts from the current client behavior and goes through the knowledge gathered about the client and only now it takes into consideration the needs of the system and go to determine the appropriate recommendation(s). These recommendations are closely related to the customer interests.

As we see there are two different directions of the process that match the recommendations. It means also different approaches to selecting the recommendation in these both cases.

The individual and group advertisement requires a way to connect the two elements of different parts of the system. This can be achieved by the structure that is used to describe the e-commerce commodities and e-commerce clients. The every commodity position is identified by appropriate hierarchical categories of properties. The preferences of the client are described by the same categories as products are. The categories in client description hold the value, which increases when the client buys a product or manifests his interest in given category. It gives the necessary connection between two different parts of the e-commerce system.

Another problem concerns indicating the appropriate individual client advertisement and supporting the catalog browser. Our proposal is to use the concept of episode. An episode contains a sequence of determinants with their values and client's preferences (the preferences of the client from collected data and current client behavior). The classification of the episodes should lead to different indicators for appropriate selection of the client- informing policy. Such broad approach allows for more flexibility and more precise selections.

Building the policy means connecting all values of described determinants with the different kinds or versions of the client-informing policy. The basic form for such relationships is the set of rules that describe the principles for choosing the appropriate client-informing policy.

The last issue is the possibility to conduct the current analysis of client responses on presented individual advertisement. It will allow evaluating the quality of client informing policy.

\section{Evaluation of the Client-informing Policy}

The evaluation of the client informing policy would be perceived as the measurement of success of ecommerce and satisfaction of customer (Spiliopoulou, 2000). The first one refers to customer loyalty, brand recognition, revenue, employee knowledge but also it refers to objective goals of e-commerce like online ordering of goods and responses to advertisement and recommendation. As it is seen the attempt to separate the measures for e-commerce and customer is not unambiguous. The customer loyalty and brand recognition measure both the success of customers that have been attracted by product and the quality of service. User satisfaction is connected with imp roved service quality.

The common intermediate measure is traffic on the website. The quest for high traffic is especially strong with e-commerce site selling advertising space but it is not out of meaning for product selling. There are three evaluation models (Cartellieri et al. 1997):

- expose (impression or unit of time spent); 
Client-informing Policy

- response (click-through);

- action (download, information exchange, transactions).

The first two models count only the quantity of attracted visitors. About the third model one can say that it is a quality model. These models offer intermediate measures that do not directly refer to the response on client-informing policy; nevertheless, data collected on web traffic can be used to conduct further analysis. The goal of this analysis is to find explanation of client behaviors in the context of visited websites, time spent at different websites, responses.

The proposal of dealing with intermediate measures has been introduced by Paul Alpar at al. (Alpar, Poremski \& Pickerodt, 1999). They have found out - on the basis of results concluded from specific empiric research (Alpar, 1998) - that web surfers are mostly looking for "good" information content. It is not easy to determine what "the best content" should offer. The solution to this problem usually is to offer as much information as possible under the restriction of time and budgets.

There are considered other metrics based on past activity, which are financial or operational measures. Tiwana and Balasubramaniam have proposed (Tiwana \& Balasubramaniam, 1999) balanced scorecard adapted to e-commerce value measurement. It integrates four perspectives:

- traditional financial measures such as profit margins and revenues;

- the value delivered to the on- line customer can be evaluated, imp roved and strengthened in relation to competing companies;

- efficacy of internal business processes and product (service) delivery logistic can be evaluated;

- knowledge gleaned from competitors can be integrated, innovative products and services can be provided and the firm can prepare itself for future contingencies and market shifts.

The problem of measuring client informing policy is an open issue. We tried to address customer value and the quality of collected knowledge about customers, that are critical to the evaluation of this policy. We focused on the customer loyalty, brand recognition, and traffic on website that directly can be referred to quality of informing policy. The important possibility of the measure discussed in the paper is that it leads to a suggestion of concrete improvements.

\section{Summary}

The idea of client-informing policy in e-commerce is an entry to this area. This paper presented the broad approach to the possibility of creating client-informing policy and the possible determinants that should develop this policy. Now we focus our work on detailed specification of the problem and drive our attention to the investigation the effectiveness of created client informing policy. The first experiences show that it can be a promising area to follow but by now it is too early for results presentation.

\section{References}

Alpar P., Poremski M., Pickerodt S. (1999). Measurement of Productivity of Web Sites, Fachbericht Nr 1999/2, PhilipsUniversity of Morburg.

Alpar, P. (1999). Satisfaction with a Web Site: Its Measurement, Factors, and Correlates. Scheer, A.W. and Nuttgens, M. (Eds.), Electronic Business Engineering, Heidelberg: Phisica-Verlag, 1999, 271-287.

Ardissono L., Goy A.(2001). Tailoring the Interaction with Users in Web Stores. User modeling and User-Adapted Intera ction 81, Kluwer Academic Publishers.

Armstrong R., Freitag D., Joachims T., Mitche, T. (1995). WebWatcher: A learning apprentice for the World-Wide Web. Proceedings of the AAAI Spring Symposium on Information Gathering from Heterogeneous, Distributed Resources. 
Sarwar B.M., Karypis G.,. Konstan J.A, Riedl J.T.(). Application of Dimensionality Reduction in Recommender System - A Case Study, http://citeseer.nj.nec.com/sarwar00application.html.

Balabanovic M., Shoham Y. (1997). Content-based, collaborative recommendation. Communications of the ACM, 40(3).

Balabanovic, M. (1997). An adaptive Web Page Recommendation Service. Proceedings of the First International Conference on Autonomous Agents. CA: Marine del Rey.

Cartellieri C., Parsons A.J., Rao V., Zeisser M.P. (1997). The real impact of Internet advertising. The McKinsey Quarterly, No.3.

Colecchia A. (1999). Defining and measuring electronic commerce. Towards the development of an OECD methodology. Proceedings of the Conference on the measurement of electronic commerce,. Singapore.

Galant V., Jakubczyc J., Paprzycki M (2002). Infrastructure for E-commerce. Proceedings of the 10th Conference Extracting Knowledge from Databases, Wroclaw: University of Economics Press, 32-47.

Good N., Schafer J.B., Konstan J.A., Borchers A., Sarwar B., Herlocker J., Riedl J. (1999). Combining Collaborative Filtering with Personal Agent for Better Recommendations. Proceedings of AAAI-99, AAAI Press.

Gordon G., Jakubczyc J, Galant V., Paprzycki M. (2002). Knowledge Management in an Ecommerce System. Proceedings of the 5th International Conference on Electronic Commerce Research, Montreal.

Gregor B., Stawiszynski M. (2002).e-Commerce, Bydgoszcz - Lódz: Oficyna Wydawnicza Branta.

Grover V., Teng J. (2001). E-commerce and the information market. Communications of the ACM, Vol.44, No.4.

Kohavi R., Provost F. (2001). Application of Data Mining to electronic Commerce. Data Mining and Knowledge Di scovery, Kluwer Academic Publishers, Boston.

Lee W.S. (2001). Collaborative Learning for Recommender Systems. Proceedings of the 18th International Conference on Machine Learning.

Lieberman H. (1995). Letizia: An agent that assists web browsing. International Joint Conference on Artificial Intelligence.

Resnik P., Varian H. R. (1997). Recommender Systems. Communications of the ACM, Vol.40, No.3.

Sarwar B., Karypis G., Konstan J., Riedl J.(2001). Item-based Collaborative Filtering Recommendation Alg orithms. http://citeseer.nj.nec.com/sarwar01itembased.html.

Sarwar B., Karypis G., Konstan J.A., Riedl J.T. (2000). Analysis of Recommendation Algorithms for E-Commerce. EC'00, Minneapolis.

Schafer J.B., Konstan J.A, Riedl J.T. (2001). E-Commerce Recommendation Applications. Data Mining and Knowledge Discovery, Kluwer Academic Publishers, Boston.

Spiliopoulou M.(2000). Tutorial on “Data analysis for web marketing and merchandizing application. PKDD’2000 Workshop, Lyon.

Spiliopoulou M., Pohle C. (2001). Data mining for measuring and improving the success of web sites. Data Mining and Knowledge Discovery, vv, 1-7, Kluwer Academic Publishers: Boston.

Szpringer W. (2002). E-commerce, e-banking. Wyzwania globalizacji. Warszawa: Diffin.

Tiwana A., Balasubramaniam R. (1999). Towards a composite metric for electronic commerce ROI: An extension of the balanced scorecard. Proceedings of the Conference on the measurement of electronic commerce, Singapore.

\section{Biographies}

Janina Jakubczyc, PhD. is a lecturer in the Faculty of Management and Computer Science, Wroclaw University of Economics, Poland. Dr Jakubczyc has authored over 30 publications mostly oriented on intelligent systems topics, temporal knowledge representation, genetic algorithms, and knowledge discovery and agent technolo gy applied in e-commerce system. In last years she has been engaged in the international project "Knowledge Acquisition and Intelligent Distributed Learning in Resolving Managerial Issues" with Belgium. Her current research is in intelligent systems with focus on agent technology in e-commerce. 


\section{Client-informing Policy}

Violetta Galant, PhD. is a lecturer in the Faculty of Management and Computer Science, Wroclaw University of Economics, Poland. Dr Galant has authored over 30 publications mostly oriented on intelligent systems topics and e-commerce system. In last years she has been engaged in the international project "Machine Learning" with Sweden. Her current research is in intelligent systems with focus on agent technology in e-commerce.

Maria A. Mach, Ph.D. is a lecturer in the Faculty of Management and Computer Science, Wroclaw University of Economics, Poland. Dr Mach has authored over 20 publications mostly oriented on integrating knowledge bases, temporal knowledge representation and intelligent systems topics. In recent years she has been engaged in the international project "Knowledge Acquisition and Intelligent Distributed Learning in Resolving Managerial Issues" with Belgium. Her current research is in intelligent systems with focus on entry barriers on the market. 